\title{
Promoting orchestral performance: the interplay between musicians' mood and a conductor's leadership style
}

\author{
SABINE BOERNER \\ UNIVERSITY OF KONSTANZ, GERMANY \\ CHRISTIAN FREIHERR VON STREIT \\ BERLIN FREE UNIVERSITY, GERMANY
}

\begin{abstract}
This study investigates the degree to which a conductor's transformational leadership and orchestral musicians' positive group mood have a beneficial effect on orchestral performance. The authors study the assertion that there is an interaction effect of conductor's transformational leadership style and group mood in the orchestra. In this view, neither the conductor's transformational leadership nor the musicians' positive group mood alone foster success; only the interaction between transformational leadership and positive group mood is effective at promoting orchestral performance. An empirical study of 208 musicians from 22 German symphony orchestras reveals the assumed interaction effect of a conductor's leadership style and musicians' group mood on the artistic quality of the orchestra.
\end{abstract}

KEYWORDS: artistic quality, cooperation, group mood, orchestra, orchestral musicians, transformational leadership

The interaction between musicians and their conductor is important for the artistic performance of a symphony orchestra (Kamerman, 1983; Lebrecht, 1991). However, little is known about the cooperation between the orchestral musicians and their conductor (Hunt et al., 2004). This study investigates the prerequisites for a high artistic performance in the orchestra on both the part of the conductor and the musicians.

Research provides some evidence concerning conductors' leadership style. Empirical data show that a non-participative, directive leadership by a conductor can enhance an orchestra's artistic quality, particularly if the musicians also perceive the conductor to be an indisputable authority in the field (Boerner and Krause, 2002). Moreover, it is empirically shown that the rating of an orchestra's artistic quality rises with the degree of expertise and power of identification that musicians attribute to their conductor (Krause et 
al., 2002). Competence, credibility and charisma have been identified as influencing musicians' attitudes and performance (Atik, 1994; Faulkner, 1973). This leads to the question of whether transformational leadership style as defined by Avolio et al. (1999) may be relevant to orchestral performance. The thesis that transformational leadership generally increases success in groups and organizations has been substantiated in the literature (De Dreu and Weingart, 2002; Fuller et al., 1996; Lowe et al., 1996). However, the effects of a conductor's transformational leadership style on the performance of an orchestra has not yet been investigated.

In respect to collaboration among musicians, high artistic quality of the orchestra requires constant process coordination - the interplay of the musicians both within a section of instruments (strings, wind and percussion) and between those sections (Weeks, 1996). Because the musicians execute their respective tasks at the same time, there is simultaneous task interdependence (Shea and Guzzo, 1987; Wageman, 1995: 146). This situation necessitates specific kinds of coordination (Saavedra et al., 1993: 62). With sequential task interdependence, only the partial results of the individual players have to be coordinated, whereas simultaneous interdependence requires the direct coordination of the contributing processes executed by the various musicians.

In substance, then, the coordination of music-making cannot be reduced to apparently 'technical' aspects such as coming in and ending the performance together. A major part of orchestral achievement is coordination in the artistic sense. Coordinating a crescendo or playing with the same articulation requires musicians to be in unison not only technically, but emotionally (Boerner, 2004; Williamon and Davidson, 2002). The musical unison necessary for a coherent interpretation by the orchestra will not be achieved until the group is emotionally in unison with itself. Since the musicians' specific task - to work out a joint interpretation of a work - is by its very nature already associated with a high level of emotionality, positive mood of the orchestra's musicians is presumably very significant to success.

Work group mood (Bartel and Saavedra, 2000) or group emotion (Barsade and Gibson, 1998) is a specific disposition developed through processes of cognitive and emotional self-regulation among group members, regardless of the type of leadership. This disposition is conceived of as a group's temporally stable, basic temperament, which can take on an overall positive or negative cast. Empirically, a uniform work group mood forms if, among other things, there is high temporal stability of the group's composition and high interdependence in the tasks of the group's members (Bartel and Saavedra, 2000).

This kind of constellation exists in a symphony orchestra, creating relatively favourable situational conditions for a unanimous group mood. First, the mobility of the members of professional orchestras tends to be low, so symphony orchestras can be regarded as groups with a high degree of stability over time. Second, the interdependence of the musicians' tasks is 
very high. Indeed, the degree of the musicians' synchronization is the very seal of an orchestra's artistic quality (Boerner, 2004). The coherence of the musical interpretation is a key feature defining the quality of a performance (Dahlhaus, 1973: 11). A unified overall sound, for example, is achievable only if all the participating musicians precisely match their intonation and dynamics as they play. An even intensification of volume (crescendo) requires all the musicians to increase their volume at the same pace. If individual musicians increase their volume too quickly or too slowly, the crescendo would destroy the unity of the orchestral sound.

This article investigates the interplay between a conductor's transformational leadership style and musicians' positive mood. It shows that neither transformational leadership by the conductor nor positive group mood of the musicians in themselves enhance the artistic quality of an orchestra. Instead, only the interaction of the conductor's transformational leadership style and positive group mood of the musicians is effective at promoting a high-quality orchestral performance.

\section{Conductors' transformational leadership and orchestral performance}

This study draws on the concept outlined by Avolio et al. (1999), according to which transformational leadership consists of three facets: charisma, inspirational motivation and intellectual stimulation. One success-enhancing effect of a transformational conductor could be that he or she provides the musicians' coordination, and, at the same time, fosters the initiative and commitment of the orchestral musicians in a special way. The reason for this conjecture becomes clear once one considers the special nature of the leadership constellation in an orchestra.

Generally, trying to manage creative processes in organizations raises the paradox that the individual creativity of the organization's members needs to be encouraged by a maximum degree of freedom but, in the interest of coordinating individual contributions, these degrees of freedom need to be constrained (Boerner and Gebert, 2005). Namely, the orchestra musicians are not usually part of working out an artistic concept for the interpretation of a work. Instead, they mainly execute the concept presented by their conductor (Boerner, 2002; Levine and Levine, 1996; Weeks, 1995). As professional orchestral musicians are highly qualified, this directive style of leadership contradicts leadership theory (Gebert, 2002) and seems likely to jeopardize the initiative and commitment of the orchestral musicians (Boerner, 2002).

It is therefore conceivable that, unlike a leader who coordinates the musicians with only a directive style, the conductor who practises transformational leadership does not simply 'dictate' his artistic concept but rather conveys it as a vision that the orchestral musicians experience as intellectual 
stimulation and inspirational motivation. In an orchestra, intellectual stimulation consists especially in interpreting familiar works in a novel way. The freshness or originality of a conductor's concept is highly stimulating mostly because orchestra musicians are generally confronted with a limited canon of familiar repertoire pieces (Auvinen, 2001: 270; Mehta, 2003: 6). The more convincing the artistic concept and the clearer the way it is communicated, the greater the inspirational motivation of the musicians (Boerner, 2002). In this manner, the conductor with a transformational style of leadership not only provides process coordination but also imbues his or her artistic concept with a persuasiveness that elicits the commitment of the orchestra members through its visionary quality, intellectual stimulation and inspirational motivation.

\section{Group mood and performance in the orchestra}

One should not suppose, however, that a conductor's transformational leadership alone is sufficient to ensure a high level of artistic achievement by an orchestra. The members of the orchestra must also experience a positive group mood so that the effect of transformational leadership can develop.

Orchestras are comparatively large and heterogeneous ensembles (Couch, 1983). The musicians of the various instruments and sections differ somewhat in their self-concepts and frequently feel greater affiliation with their own section than with the orchestra. It cannot be assumed that a shared social identity (Tajel, 1981) forms on its own among the orchestral musicians. Within the orchestra there are also differences between the rankand-file members (tutti), section leaders and soloists as far as hierarchy and remuneration are concerned. Other differences exist in terms of seniority, age, nationality, and artistic and technical level of the individual musicians. According to findings from diversity research, heterogeneous teams can be advantageous for group performance but serious barriers to cooperation can build and then complicate group achievement (Gebert et al., in press; Williams and O'Reilly, 1998).

In order to achieve high artistic quality, an orchestra must synchronize its playing precisely, a goal that calls upon the musicians to be in unison both cognitively and emotionally. This is where positive group mood among the musicians comes in. Generally, a positively coloured group mood has been shown to foster the willingness of the group members to help each other. There is a significant positive correlation between positive mood (defined by adjectives such as 'open', 'friendly' and 'kind'), as opposed to negative mood ('very reserved', 'irritable' and 'discouraging'), and organizational citizenship behaviour (Isen and Baron, 1991; Müller and Bierhoff, 2001). In the orchestra, organizational citizenship behaviour can take many different forms. For example, musicians may assist one another with job-related or even personal matters. They may pitch in and help those who have been 
absent or who are new to the ensemble, they may assist those experiencing especially heavy work loads. Positive mood of the musicians thus appears to promote success from the motivational standpoint alone.

The decisive effect of positive group mood in an orchestra, however, is that this emotional unison ultimately forges the requisite unified sound. This ability is essential if the conductor's efforts to shape the artistic interpretation of an orchestral work are to bear fruit.

In summary, neither positive group mood of the musicians nor transformational leadership by the conductor are sufficient on their own to achieve high levels of artistic achievement by an orchestra. Metaphorically speaking, positive group mood ensures that the orchestral musicians behave like one instrument. This effect, though, represents potential only, which by itself does not elicit artistic achievement. What is needed is the conductor who knows how to play this instrument. Conversely, even a virtuoso conductor is not enough to ensure high artistic quality if his instrument is incapable of delivering it.

These arguments and research lead to the formulation of two hypotheses on the interaction effect that a conductor's transformational leadership and musicians' positive group mood have on an orchestra's artistic quality.

Hypothesis 1 The conductor's transformational leadership style fosters the artistic quality of an orchestra's achievement only if it is accompanied by highly positive group mood among the musicians.

Hypothesis 2 Positive group mood among the musicians fosters the artistic quality of an orchestra's achievement only if it is accompanied by the conductor's transformational leadership style.

\section{Method}

\section{PARTICIPANTS}

These two hypotheses were tested through written questionnaires administered to 208 musicians (70\% male) from 22 German symphony orchestras in 2002 and 2003 (Von Streit, 2003). Because the managing boards of the orchestras (mainly orchestras in opera companies) were personally contacted for this purpose, the return rate of the questionnaires was 76 percent. The participating orchestras had an average membership of 98 musicians (SD = 17), with no more than 12 musicians per orchestra being included in the study. The average age of the respondents was 40 years $(\mathrm{SD}=8.83)$ with an average length of professional experience in an orchestra of 15 years ( $\mathrm{SD}=9.39)$. The musicians belonged to different instrumental sections (strings $62 \%$, wind $36 \%$, percussion $2 \%$ ) and functions (tutti players $67 \%$ and soloists/section leaders $33 \%$ ). 


\section{OPERATIONALIZATION OF THE CONSTRUCTS}

A questionnaire was developed to measure the conductor' s transformational leadership style, the group mood among the musicians and the artistic quality of the orchestra (recorded on a 7-point scale). Because the mood among the musicians and the artistic quality of an orchestral performance are purposefully ascertainable only at the group level (the orchestra as a whole), the data were not calculated at the individual level. For each orchestra, the responses by the musicians were aggregated into a mean score on the constructs of interest in this study (transformational leadership, group mood of the musicians and the artistic quality of the ensemble). The coefficient $r_{W G(J)}$ (James et al., 1984) was used to test the admissibility of the aggregation of the individual responses at the orchestral level. This procedure permits the aggregation of data as a function of the agreement between the responses of the participants per orchestra (Kozlowski and Hattrup, 1992: 162).

The conductor's transformational leadership was operationalized by two items for each of the three facets of transformational leadership identified by Avolio et al. (1999) - charisma (has charisma; we are proud to work with him), inspirational motivation (clarifies his objectives with imagery and gestures; makes it clearly understandable to us what he wants of us) and intellectual stimulation (often makes completely new, convincing suggestions for interpretation; enables us to see familiar works in a new light). Since the three scales correlate at about $r=.80$ in the literature (see Avolio et al., 1999: 455 ), the construct was assumed to be one-dimensional. The mean coefficient of the scale for transformational leadership, $r_{W G(J)}$, was .82 , which indicates a high degree of agreement within the orchestra (James et al., 1984) and thus justifies the decision to aggregate the individual responses to these items into a measure of transformational leadership at the group level (Bliese, 2000; Kozlowski and Hattrup, 1992). Group mood was measured with eight items: at variance $\mathrm{e}^{\mathrm{R}}{ }^{1}$ likeable; incapable ${ }^{\mathrm{R}}$; hold to each other well; pleasant; lazy; there are tensions here between the sections ${ }^{\mathrm{R}}$; the various groups in the orchestra hold to each other well (Cronbach's $\alpha=.94 ; r_{W G(J)}=.88$ ).

The artistic quality of the orchestra served as the measure of the ensemble's achievement (Auvinen, 2001: 274). As in earlier studies (Boerner and Krause, 2002; Krause et al., 2002), the attempt was not to measure the artistic quality itself but rather the reaction of third parties to the orchestra's achievement (We would like to know how you think the artistic quality of your orchestra is rated - taking most of the performances into consideration; the public generally judges the quality of our orchestra as . . .; others who play with us, e.g. soloists, generally judge the quality of our orchestra as . . .). The quality of the orchestra was also compared to other orchestras of the same quality (Compared to other orchestras rated in the same quality category, the artistic quality of our orchestra is . . .). For each of the 22 orchestras represented in the study, this last assessment was undertaken by at 
least two additional musicians who had not already rated the conductor's transformational leadership style and the group mood among the musicians. The mean of this perceived quality rating for each orchestra was used to measure this aspect of orchestra quality (Cronbach's $\alpha=.73 ; r_{W G(J)}=.92$ ).

\section{Results}

Table 1 shows descriptive statistics and intercorrelations of all variables.

TABLE 1 Descriptive statistics, intercorrelations, reliabilities and $r_{W G(J)}$ of all variables $(N=22)$

\begin{tabular}{lrrr}
\hline Variable & 1 & 2 & 3 \\
\hline 1. Artistic quality & & & \\
2. Conductor's transformational leadership & $.38^{*}$ & & \\
3. Positive group mood of the musicians & $.56^{* *}$ & $.42^{*}$ & \\
$\bar{\chi}$ & 5.58 & 4.57 & 4.64 \\
S & .59 & 1.45 & .84 \\
Cronbach's alpha & .73 & .94 & .94 \\
$r_{\mathrm{WG}(\mathrm{J})}$ & .92 & .82 & .88 \\
\hline
\end{tabular}

${ }^{*} p<.01 ; * * p<.10$.

To test the hypotheses, we conducted a multiple hierarchical regression analysis with artistic quality of the orchestra regressed on musicians' positive group mood, conductor's transformational leadership style and their interaction (see Table 2). To avoid multicollinearity between the predictors and the interaction terms, we centred the predictor variables around zero and multiplied them to form the interaction term (Aiken and West, 1991).

TAB LE 2 Multiple regression analyses. Dependent variable: the artistic quality of the orchestra $(\mathrm{N}=22)$

\begin{tabular}{lll}
\hline Step and variable & Model 1 & Model 2 \\
\hline 1. Positive group mood & $.48^{* *}$ & $.48^{* *}$ \\
2. Transformational leadership & .18 & .14 \\
3. Positive group mood x transformational leadership & & $.51^{* *}$ \\
$R^{2}$ & $.34^{*}$ & $.60^{* *}$ \\
$\Delta R^{2}$ & & $.26^{* *}$ \\
\hline
\end{tabular}

Standardized regression coefficients are reported.

$* p<.05 ; * * p<.01$.

There is no significant main effect of the conductor's transformational leadership style on the artistic quality of the orchestra in both model 1 and model 2. Instead, as predicted (hypothesis 1), model 2 reveals a significant 


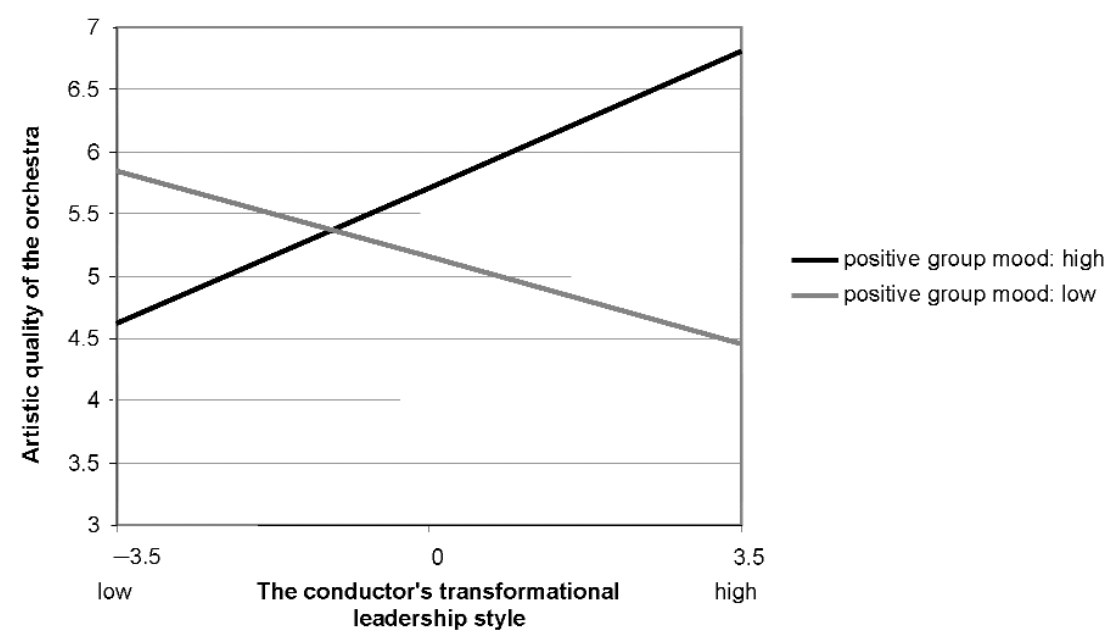

FIGURE 1 Interaction of conductor's transformational leadership style and musicians' positive group mood on the artistic quality of an orchestra.

interaction effect between transformational leadership and positive group mood on the artistic quality of the orchestra. The form of this significant interaction effect is shown in Figure 1. Additionally, both models reveal a significant main effect of musicians' positive group mood on the artistic quality of the orchestra. Although, in the case of a significant interaction effect, the main effects should not be interpreted equally (Jaccard and Turrisi, 2003: 24), the significant main effect of positive group mood on the artistic quality of the orchestra (see Table 2) may reflect a well-known phenomenon: good orchestras - those with positive group mood, partly meaning that the members work extremely well together as a team - can attain high levels of artistic achievement regardless of the transformational leading conductor, sometimes largely ignoring a 'poor' one.

\section{Discussion}

First, it must be said that our sample of German orchestras does not represent a random selection. This raises the question of to what extent the results found for German musicians are representative for musicians from other countries. We cannot, however, answer this question at this stage since no scientifically founded results exist so far. It would be interesting for further studies to test if the relationships that were found between leadership behaviour, musicians' mood and artistic quality of the orchestra are valid for orchestras in other countries as well, or if the results only represent specific German characteristics. To gain knowledge on this question, however, cross-cultural comparative studies would have to be conducted on various orchestras. 
Another methodological limitation of this study is that a longitudinal design for measuring dependent and independent variables at different times over an extended period would have been more revealing. A third inherent problem is the measurement of an orchestra's artistic quality. Building on experience from earlier studies (Boerner and Krause, 2002; Krause et al., 2002), this study included additional independent ratings of artistic quality. This change did not completely circumvent single subject method consistency bias (McDonald, 1999), though it did at least mitigate the problem. However, the combination of data sources that this study used to assess artistic quality is apt to jeopardize the reliability of the construct. It would therefore be desirable for future studies to measure artistic quality exclusively from the perspective of additional sources.

Given these limitations, the present study reveals the interplay between the musicians and the conductor showing that both are partially dependent on each other. In this sense, the present study helps to clarify the conditions under which both positive group among musicians and conductor's transformational leadership style can contribute to the success of an orchestra. In other words, the cooperation between the musicians of a symphony orchestra and their conductor can be interpreted as an example of positive synergy.

The interaction effect between conductor's transformational leadership style and positive mood among musicians on the artistic quality of the orchestra found in this study can be interpreted as follows: the conductor's transformational leadership style has a positive effect on the artistic quality of an orchestra only if there is a high positive group mood among the orchestral musicians. If there is a low positive mood group among the orchestral musicians, increasing transformational leadership by the conductor does not lead to an increase in an orchestra's artistic quality. In this case, even a conductor with a highly pronounced transformational leadership style cannot increase the artistic quality of an orchestra. Conversely, positive group mood among the musicians enhances their orchestra's artistic quality only if the conductor's transformational leadership is also highly pronounced. Consequently, our study reveals that the process coordination provided by the transformational leading conductor has to be accompanied by the musicians' self-coordination to attain high artistic quality and vice versa.

NOTE
$1 \quad \mathrm{R}=$ polarity reversed.

ACKNOWLEDGEMENTS

The authors wish to acknowledge valuable advice from Diether Gebert, Berlin Technical University, the editor and two anonymous reviewers. 
REFERENCES

Aiken, L.S. and West, S.G. (1991) Multiple Regression: Testing and Interpreting Interactions. Newbury Park, CA: Sage.

Atik, Y. (1994) 'The Conductor and the Orchestra: Interactive Aspects of the Leadership Process', Leadership and Organization Development Journal 15(1): $22-8$.

Auvinen, T. (2001) 'Why Is It Difficult to Manage an Opera House? The Artistic-Economic Dichotomy and its Manifestations in Organizational Structures of Five Opera Organizations', Journal of Arts Management, Law and Society 30(4): 268-82.

Avolio, B.J., Bass, B.M. and Jung, D.I. (1999) 'Re-examining the Components of Transformational and Transactional Leadership using the Multifactor Leadership Questionnaire', Journal of Occupational and Organizational Psychology 72: 441-62.

Barsade, S.G. and Gibson, D.E. (1998) 'Group Emotion: A View from Top and Bottom’, in M.A. Neale and E.A. Mannix (eds) Research on Managing Groups and Teams, pp. 81-102. Stanford, CA: JAI Press.

Bartel, C.A. and Saavedra, R. (2000) 'The Collective Construction of Work Group Moods', Administrative Science Quarterly 45: 197-231.

Bliese, P. (2000) 'Within-Group Agreement, Non-independence, and Reliability', in K.J. Klein and S.W.J. Kozlowski (eds) Multilevel Theory, Research, and Methods in Organizations, pp. 349-81. San Francisco: Jossey-Bass.

Boerner, S. (2002) Führungsverhalten und Führungserfolg - ein Beitrag zu einer Theorie der Führung am Beispiel des Musiktheaters. Wiesbaden: Gabler.

Boerner, S. (2004) 'Artistic Quality in an Opera Company - Towards the Development of a Concept', Nonprofit Management and Leadership 4(4): 425-36.

Boerner, S. and Gebert, D. (2005) 'Organizational Culture and Creative Processes: Comparing German Theatre Companies and Scientific Institutes', Nonprofit Management and Leadership 16(2): 209-220.

Boerner, S. and Krause, D.E. (2002) 'Führung im Orchester: Kunst ohne künstlerische Freiheit? Eine empirische Untersuchung', Zeitschrift für Personalforschung 16(1): 90-106.

Couch, S.R. (1983) 'Patronage and Organizational Structure in Symphony Orchestras in London and New York', in J.B. Kamerman and R. Martorella (eds) Performers \& Performances: The Social Organization of Artistic Work, pp. 109-22. South Hadlye, MA: Bergin.

Dahlhaus, C. (1973) ‘Über musikalische Werturteile’, in W. Krützfeld (ed.) Wertproblematik der Musikdidaktik, pp. 9-18. Ratingen: Henn.

De Dreu, C.K.W. and Weingart, L.R. (2002) 'Task versus Relationship Conflict, Team Performance, and Team Member Satisfaction: A Meta-Analysis', paper presented at the Academy of Management Meeting, Denver, August.

Faulkner, R. (1973) 'Orchestra Interaction: Some Features of Communication and Authority in an Artistic Organization', Sociological Quarterly 14: 147-57.

Fuller, J.B., Patterson, C.E.P., Hester, K. and Stringer, D.Y. (1996) 'A Quantitative Review of Research on Charismatic Leadership', Psychological Reports 78: 271-87.

Gebert, D. (2002) Führung und Innovation. Stuttgart: Kohlhammer.

Gebert, D. (2004) Innovation durch Teamarbeit - ein kritische Bestandsaufnahme. Stuttgart: Kohlhammer. 
Gebert, D., Boerner, S. and Kearney, E. (in press) 'Crossfunctionality and innovation in new product development teams: The dynamics of the dilemmatic structure and consequences for the management of diversity. European Journal of Work and Organizational Psychology.

Hunt, J.G., Stelluto, G.E. and Hooijberg, R. (2004) 'Toward New-Wave Organization Creativity: Beyond Romance and Analogy in the Relationship between Orchestra-Conductor Leadership and Musician Creativity', Leadership Quarterly 15: 154-62.

Isen, A.M. and Baron, R.A. (1991) 'Positive Affect as a Factor in Organizational Behavior', in B.M. Staw and L.L. Cummings (eds) Research in Organizational Behavior, pp. 1-53. Greenwich, CT: JAI Press.

Jaccard, J. and Turrisi, R. (2003) Interaction Effects in Multiple Regression. 2nd edn. Thousand Oaks, CA: Sage.

James, L.R., Demaree, R.G. and Wolf, G. (1984) 'Estimating Within-Group Interrater Reliability With and Without Response Bias', Journal of Applied Psychology 69: 85-98.

Kamerman, J.B. (1983) 'Symphony Conducting as an Occupation', in J.B. Kamerman and R. Martorella (eds) Performers \& Performances: The Social Organization of Artistic Work, pp. 43-56. South Hadlye, MA: Bergin.

Kozlowski, S.W. and Hattrup, K. (1992) 'A Disagreement about Within-Group Agreement: Disentangling Issues of Consistency versus Consensus', Journal of Applied Psychology 77: 161-7.

Krause, D.E., Boerner, S., Lanwehr, R. and Nachtigall, C. (2002) 'Strukturgleichungsmodelle zur Analyse von Macht und Führungserfolg im Orchester', Zeitschrift für Personalpsychologie 1: 124-37.

Lebrecht, N. (1991) Der Mythos vom Maestro. Zürich: M\&T Verlag.

Levine, S. and Levine, R. (1996) 'Why They're Not Smiling: Stress and Discontent in the Orchestra Workplace, Harmony 2: 15-25.

Lowe, K.B., Kroeck, K.G. and Sivasubramaniam, N. (1996) 'Effectiveness Correlates of Transformational and Transactional Leadership: A Meta-analytic Review of the MLQ Literature', Leadership Quarterly 7(3): 385-425.

McDonald, R.P. (1999) Test Theory: A Unified Treatment. Mahwah, NJ: Erlbaum.

Mehta, Z. (2003) 'Managing the New York Philharmonic in Today's World', International Journal of Arts Management 5(3): 4-11.

Müller, G.F. and Bierhoff, H.W. (2001) 'Stimmungseinflüsse in Projektgruppen', in R. Fisch, D. Beck and B. Englich (eds) Projektgruppen in Organisationen, pp. 323-36. Göttingen: Verlag für Angewandte Psychologie.

Saavedra, R., Earley, P.C. and Van Dyne, L. (1993) 'Complex Interdependence in Task-Performing Groups', Journal of Applied Behavioral Psychology 78(1): $61-72$.

Shea, G.P. and Guzzo, R.A. (1987) 'Groups as Human Resources', in K.M. Rowland and G.P. Ferris (eds) Research in Human Resources and Personal Management, pp. 323-56. Greenwich, CT: JAI Press.

Tajfel, H. (1981) Human Groups and Social Categories: Studies in Social Psychology. Cambridge: Cambridge University Press.

Von Streit, C. (2003) 'Untersuchung zum Arbeitsklima in deutschen Kulturorchestern - eine bundesweite Fragebogenstudie', unpublished master's thesis, Free University of Berlin, Germany.

Wageman, R. (1995) 'Interdependence and Group Effectiveness', Administrative Science Quarterly 40: 145-80. 
Weeks, P. (1995) 'A Rehearsal of a Beethoven Passage: An Analysis of Correction Talk', Research in Language and Social Interaction 29(3): 247-90.

Weeks, P. (1996) 'Synchrony Lost, Synchrony Regained: The Achievement of Musical Co-ordination', Human Studies 19: 199-228.

Williamon, A. and Davidson, J.W. (2002) 'Exploring Co-performer Communication', Musicae Scientiae 1(1): 53-72.

Williams, K.Y. and O’Reilly (1998) 'Demography and Diversity in Organizations', Research in Organizational Behavior 20: 77-140.

SABINE BOER NER is a Professor at the University of Konstanz, Faculty of Politics and Management, as well as Chair of Management, especially leadership and strategy. Her research interests include leadership, organizational behaviour and the management of cultural industries. She has published a number of books and papers in German and international journals on organization behaviour and management.

Address: Faculty of Politics and Management, Fach D88, Universitätsstrasse 10, 78457 Konstanz, Germany. [email: sabine.boerner@uni-konstanz.de]

CHRISTIAN FREIHERR VON STREIT is a student in the Faculty for Educational Psychology, Berlin Free University. He wrote his master's thesis on collaboration in symphony orchestras and has published papers in proceedings of international conferences about music psychology.

Address: Faculty for Educational Psychology, Berlin Free Unversity, Habelschwerdter Allee 45, 14195 Berlin, Germany. [email: Christian.v.streit@gmx.de] 